\title{
Synthesis and Characterization of Maghemite as an Anode for Lithium-Ion Batteries
}

\author{
M. Golmohammad ${ }^{1,2, *}$, F. Golestanifard ${ }^{1}$, A. Mirhabibi $^{1,3}$ \\ ${ }^{1}$ School of Metallurgy and Materials Engineering, Iran University of Science and Technology (IUST), \\ Tehran, Iran \\ ${ }^{2}$ Faculty of Applied Sciences, Delft University of Technology, Delft, Netherlands \\ ${ }^{3}$ Institute for Materials Research (IMR), University of Leeds, Leeds, United Kingdom \\ *E-mail: $\underline{\text { m_golmohammad@iust.ac.ir }}$
}

doi: $10.20964 / 2016.08 .55$

Received: 9 April 2016 / Accepted: 12 June 2016 / Published: 7 July 2016

\begin{abstract}
Thermal decomposition method were used to synthesize magnetite nanoparticles which then oxidized to maghemite. Simultaneous thermal analysis, X-ray diffraction, and Fourier transform infrared spectroscopy disclosed the formation of iron-urea complex and also revealed pathway of iron oxide formation from iron-urea complex in thermal decomposition method. It was demonstrated that the iron-urea complex calcined at $450^{\circ} \mathrm{C}$ in argon resulted in the formation of magnetite. The magnetite were heated at $230^{\circ} \mathrm{C}$ for $2 \mathrm{~h}$ to be oxidized to maghemite. The formation of maghemite were confirmed using Mössbauer spectroscopy. The average particle size of obtained maghemite was estimated $43 \mathrm{~nm}$ using field emission scanning electron microscopy and high-resolution transmission electron microscopy. The anode body was doctor bladed using maghemite with carbon black and polyvinylidene difluoride powder. Electrochemical performance of this anode in lithium-ion battery was further investigated by cyclic voltammetry and galvanostatic charge-discharge. Galvanostatic charge-discharge cycling at current density of $50 \mathrm{~mA} \mathrm{~g}^{-1}$ showed a reversible capacity of $538 \mathrm{mAh} \mathrm{g}^{-1}$. The reason for this competent performance was thought to be dependent upon the size of particles.
\end{abstract}

Keywords: Maghemite; lithium-ion battery; anode; thermal decomposition; nanoparticles

\section{$\underline{\text { FULLTEXT }}$}

(C) 2016 The Authors. Published by ESG (www.electrochemsci.org). This article is an open access article distributed under the terms and conditions of the Creative Commons Attribution license (http://creativecommons.org/licenses/by/4.0/). 